\title{
Interfaces entre a Pedagogia do Teatro e os Estudos da Performance
}

\author{
Relations between Theatre Pedagogy and Performance Studies
}

Luciana Hartmann*

Universidade de Brasília

Resumo Este texto propõe o debate sobre pontos de contato entre a nova terminologia utilizada nos processos de ensino-aprendizagem em teatro, a Pedagogia do Teatro e os Estudos da Performance. Partindo de uma análise dos Parâmetros Curriculares Nacionais (PCN Arte I e II) e das perspectivas histórico-críticas trazidas por alguns dos principais pesquisadores brasileiros que tem se dedicado ao tema, busca-se, ao longo do texto, refletir sobre as contribuições que os Estudos da Performance podem trazer para o desenvolvimento do campo da Pedagogia do Teatro.

PALAVRAS-CHAVE: Pedagogia do teatro, performance, arte-educação.

Abstract This paper proposes the debate about contact points between the new terminology used in the in theater teaching-learning process, the Theatre Pedagogy, and the Performance Studies. Based on an analysis of the Brazilian National Curriculum Parameters (PCN Art I and II) and the historical-critical perspectives brought by some of the leading Brazilian researchers who has been dedicated to this issue, we seek to reflect on the contributions that the Performance Studies can bring to the field of Theatre Pedagogy.

KEYWORDS: Theatre pedagogy, performance, art-education. 
Os primeiros estímulos para a redação deste artigo vieram diretamente da sala de aula. Como professora da área de Licenciatura do Curso de Artes Cênicas da UnB, percebi a necessidade de contextualizar aos estudantes essa nova categoria que passou a ser empregada há alguns anos no Brasil, para definir o lugar específico do teatro no amplo campo da Arte-Educação. A assim chamada Pedagogia do Teatro permite, em minha perspectiva, uma reflexão mais acurada dos processos de ensino -aprendizagem, de criação e transmissão de saberes próprios ao Teatro, dentro e fora da sala de aula. Por outro lado, minha experiência como antropóloga, trabalhando há mais de quinze anos com contadores de histórias tradicionais sob a perspectiva dos Estudos da Performance, me impulsionou a pensar nos cruzamentos possíveis entre estes e a Pedagogia do Teatro. A partir, portanto, de leituras, reflexões e debates, realizados com alunos e colegas professores, pretendo desenvolver, aqui, um breve panorama acerca da relação entre Teatro e o campo da Arte-Educação no Brasil, acompanhado de uma breve análise dos Parâmetros Curriculares Nacionais para o Ensino do Teatro (PCN Arte I e II). Na sequência, realizo um levantamento histórico-crítico do termo Pedagogia do Teatro, amparada em trabalhos de pesquisadores da área para, finalmente, fazer algumas primeiras inferências sobre sua relação produtiva com os Estudos da Performance.

\section{O Teatro e a Arte-Educação: o lugar da diferença}

Gostaria de iniciar pensando a relação entre o Teatro e a Educação e os múltiplos significados que têm sido atribuídos a esta. Acredito que somente a partir do estabelecimento de uma base em relação aos conceitos é que poderemos avançar no debate e implementar propostas mais afinadas com as reflexões que vem sendo produzidas na Arte-Educação contemporânea. ${ }^{1}$

O ensino de Artes no Brasil esteve pautado, em grande medida, numa produção relacionada às Artes Plásticas (desenho, pintura, escultura, etc.). A própria ideia de polivalência trazida pelos cursos de Educação Artística, implementados a partir de 1971, resultou numa proposta dificilmente aplicável, que teve como consequência prática a priorização, por parte dos professores, do ensino de Artes Plásticas. Como esta é uma área que tem uma longa e sólida tradição de ensino e pesquisa, é natural que acabasse se estabelecendo como referência para as demais linguagens artísticas. No entanto, diante da insatisfação gerada por esta ênfase, e da lacuna deixada no que diz respeito ao espectro da aprendizagem de Arte na escola, foram implantados, em 1998, os novos Parâmetros Curriculares Nacionais, que reconhecem as especificidades dos demais campos de saber da área: Dança, Música e Teatro, juntamente com as Artes Visuais, como linguagens artísticas. Neste sentido, torna-se importante que trabalhemos na perspectiva de sistematizar os conhecimentos da linguagem teatral, para que possamos melhor compreender as especificidades de nosso campo de atuação. Antes de adentrarmos na análise mais específica dos PCN Arte, no entanto, devemos revermos a própria relação entre o Teatro e a Educação e os múltiplos significados que têm sido atribuídos a ela.

Historicamente, os fundamentos do Teatro na Educação foram estabelecidos sob a perspectiva do campo da Educação. Atualmente, essa relação se inverte, pois 
são os conteúdos e metodologias específicas do Teatro que direcionam a reflexão e prática teatral dentro e fora de sala de aula. A partir da reestruturação da relação entre a Arte e a Educação, passamos da denominação "Educação Artística" para "Arte". Dessa forma, de atividade educativa atingimos o estatuto de disciplina e do "Teatro-Educação" chegamos então à Pedagogia do Teatro.

Esse processo de mudança conceitual, da mesma forma que reflete uma transformação nas posturas em relação ao ensino-aprendizagem de Teatro, também deve refletir, influenciar e gerar novas abordagens nesse campo de atuação. A nova terminologia utilizada - Pedagogia do Teatro - propõe novas posturas e novos sentidos para nosso papel como educadores de/em Teatro.

O discurso sobre Arte-Educação no Brasil amadureceu e se transformou ao longo do tempo, em grande parte como resultado das reflexões ocorridas em congressos da Associação e da Federação de Arte-Educadores Brasileiros (FAEB), acompanhando as transformações sociais, políticas e ideológicas sofridas pelo Brasil nos últimos quarenta anos. Da crença na educação como uma forma neutra de transmissão e construção de conhecimentos, passamos pela crise das ideologias e pela compreensão de que toda atitude, postura ou comportamento - inclusive dos docentes - será sempre parcial. Chegamos no período que Sandra Mara Corazza (2003) chama do "desafio da diferença pura”: a educação em tempos pós-modernos se veria obrigada a confrontar os currículos, as didáticas e as metodologias com elementos mais culturais e menos escolares. Este é um ponto fundamental para pensarmos nesse novo lugar que a Arte e, mais especificamente, o Teatro, ocupa na contemporaneidade: não se pode mais buscar respostas ou soluções absolutas, pois as questões que se colocam em distintos contextos não são, definitivamente, as mesmas. A percepção de que somos sujeitos, produtores e produtos de culturas, sociedades, tempos, espaços geográficos, religiões, economias, sistemas políticos, não pode mais estar separada de nossa atuação docente.

Essa discussão nos leva a pensar sobre o desafio da chamada "educação multicultural". O multiculturalismo, que parte do prefixo multi, está calcado, na perspectiva da arte-educação, no respeito às tradições culturais, artísticas e estéticas dos estudantes, ou seja, na contextualização de suas origens e de seus grupos sociais. Também entendido como pluralidade cultural, este é um dos temas transversais previstos nos Parâmetros Curriculares Nacionais. O conceito chega ao Brasil através de discussões que emergiram nos EUA e na Europa, visando a solução de conflitos sociais (preconceito racial, étnico, de classe, etc.), com foco na realidade escolar. No Brasil, o conceito encontra reverberação em questões como a desigualdade social e a discriminação encobertas, por exemplo, pelo "mito das três raças". ${ }^{2}$

A necessidade de contextualização, que é fortemente defendida por algumas das principais correntes da educação contemporânea, é também uma das grandes - e talvez principais - bandeiras da antropologia. Sem contextualização não há possibilidade de compreensão dos processos sociais, e sem essa compreensão não há possibilidade de se atingir uma comunicação democrática e frutífera entre as diferentes culturas. Transportando esta questão para a sala de aula, podemos pensar que se para a antropologia a ideia de educação pode compreender os processos formais e informais 
pelos quais a cultura é transmitida aos indivíduos, a Educação Multicultural seria o processo pelo qual uma pessoa desenvolve competências em múltiplos sistemas de perceber, avaliar, acreditar e fazer (RICHTER, 2007, 86). A compreensão destes processos, por parte do docente de arte e sua introdução no ambiente de ensino-aprendizagem, permite maior riqueza no desenvolvimento das atividades didáticas, ao mesmo tempo em que democratiza e valoriza os conhecimentos de cada aluno/aluna. Nesta proposta, o/a aluno/aluna deixa de ser visto como uma tábula rasa a ser preenchida e passa a ser respeitado/a como um sujeito que pode compartilhar, dar e receber saberes de ordens diversas. Essa forma de "multiculturalismo como política aplicada" (GUSMÃO, 2008), acredito, pode ser pensada como um dos pontos de contato entre a educação (e, consequentemente, a Pedagogia do Teatro) e os Estudos da Performance, sobretudo pela abordagem das poéticas e políticas de aprendizagem, desenvolvida por Elyse Lamm Pineau em seu belo artigo "Nos cruzamentos entre a Performance e a Pedagogia: uma revisão perspectiva” (2010). ${ }^{3}$ Esse aspecto será retomado adiante.

\section{Uma breve análise dos Parâmetros Curriculares Nacionais para o Ensino do Teatro}

Embora desde o período do Brasil colônia se tenha notícia do uso do teatro na educação formal (CACCIAGLIA, 1986; CAFEZEIRO, 1996), e, num sentido mais amplo, nos processos não-formais de aprendizagem, a presença efetiva do teatro na escola só ocorreu de fato a partir da lei 5692/71, que estipula a obrigatoriedade da Educação Artística. Uma ação concreta no sentido de definir as especificidades do ensino de Teatro, no entanto, só ocorre a partir da instauração dos PCN-Arte I e II, no ano de 2000.

Em texto de 2001, Arão Paranaguá de Santana, professor de Teatro da UFMA, e Yara Rosas Peregrino, professora do Departamento de Artes e Educação da UFPB, desenvolvem uma elucidativa análise crítica da proposta dos PCN. Um dos primeiros aspectos - negativos - considerados pelos autores é que as considerações introdutórias da parte de teatro no documento para as séries iniciais são muito vagas, podendo servir para qualquer outra área de conhecimento. Por outro lado, os autores veem como positiva a preocupação dos $\mathrm{PCN}$ em ressaltar a importância que o conhecimento específico das etapas do desenvolvimento da linguagem dramática e sua relação com o processo cognitivo têm para o ensino de teatro - que não ocorre, por exemplo, em relação às outras áreas, como Artes Visuais, que, em geral, determinam as perspectivas de abordagem em artes. No entanto, é criticada a falta de contextualização desta opção epistemológica que, para os autores, parece aproximar-se do construtivismo, ignorando, portanto, outras trajetórias da teoria curricular contemporânea (PEREGRINO; SANTANA, 2001, 99). Outro aspecto levantado pelos autores é a falta de definição das vertentes teóricos e metodológicas que orientam a inclusão dos jogos na prática educacional em teatro.

Ainda, em relação aos $\mathrm{PCN}$, um aspecto positivo ressaltado pelos autores, nas propostas para os diferentes níveis, diz respeito à orientação no sentido de aproximar a vivência do aluno de sua prática em sala de aula, ou seja, a contextualização dos conteúdos curriculares de Arte/Teatro de acordo com a realidade sociocultural dos 
alunos. Embora partindo desta necessária contextualização, que permite que os conteúdos adquiram significado, os PCN não restringem o processo educacional em Arte a este aspecto, propondo, também, que se oportunize aos alunos experiências artísticas diferenciadas, permitindo a ampliação de seu universo de apreciação e a consequente produção de um pensamento crítico.

É possível constatar, neste sentido, um alinhamento dos PCN-Arte à Abordagem Triangular, proposta, teórico-metodológica, sistematizada por Ana Mae Barbosa (1991) que integra, através de três diferentes eixos, o fazer artístico (eixo produção), a análise de obras e objetos de arte (eixo apreciação/reflexão) e a história da arte (eixo contextualização). Embora elaborada a partir do campo das Artes Visuais, a Abordagem Triangular tem sido utilizada na elaboração de diretrizes e parâmetros para o ensino-aprendizagem das artes em suas diversas linguagens, motivando na área de Teatro, reações diversas, que vão de elogios, a críticas e propostas alternativas.

Analisando os PCN-Arte sob a perspectiva desta Abordagem, por exemplo, Peregrino e Santana $(2001,104)$ observam que na sessão relativa ao Teatro no Ensino Fundamental (PCN-Arte I) os conteúdos não estão situados claramente em cada um dos eixos, o que pode dificultar uma condução sistemática destes por parte dos professores. Já no documento relativo ao Ensino Médio, os autores consideram que as especificidades da linguagem estão contempladas, pois os conteúdos encontram-se relacionados de maneira mais direta aos três eixos norteadores, cujos conceitos, embora alterados neste nível de ensino para produção, apreciação e contextualização, não diferem sensivelmente em seu conteúdo semântico e função.

Já para Ingrid Koudela, os PCN-Arte, ao incorporarem como eixos de aprendizagem a apreciação estética e a contextualização, somadas à expressividade/ produção de arte pela criança e pelo jovem, representam um grande avanço. De acordo com ela, "essa proposta vem promovendo o potencial do Teatro como exercício de cidadania e o crescimento da competência cultural dos alunos" (2002: 234). Koudela ressalta a importância da inclusão do eixo "apreciação", a partir do qual a questão do papel do receptor e da relação dialógica gerada através das obras de arte são particularmente valorizadas. Desta forma, o Teatro no processo educacional passa a ser pensado não apenas enquanto ação (exercícios de improvisação, jogos, montagens de espetáculos), mas também como recepção (assistir espetáculos, analisá-los, criticá-los). A autora aponta, ainda, que o efetivo deslocamento para o teatro - sala de espetáculos - possibilita aos alunos uma experiência estética diferenciada, pois os coloca em contato direto com a totalidade dos elementos que compõem um espetáculo: iluminação, sonoplastia, cenografia, maquiagem, atuação, dramaturgia, direção, entre outros. Vale lembrar que todos estes elementos podem ser, na volta à sala de aula, ricamente aproveitados como objetos de análise. E, na medida em que os alunos tenham experiências estéticas diferenciadas, maior será sua compreensão e domínio da linguagem teatral.

Nessa reflexão sobre os PCN-Arte é importante problematizar também as consequências geradas pela ênfase do trabalho teatral, especialmente em sala de aula, no processo expressivo e não no produto dramático. Para Biange Cabral, esta perspectiva de trabalho obscureceria a ideia do teatro como "arte e ofício". Para além da crítica, 
a proposta de relacionar arte a trabalho, a um saber específico, é valiosa e pode/deve ser utilizada na busca pela legitimação do teatro - e de suas especificidades - no ambiente escolar. Os processos de ensino/aprendizagem em Teatro e, sobretudo, de troca e conhecimentos que marca o desenvolvimento destes em sala de aula, só tem a ganhar com essa abordagem mais igualitária e equilibrada de seus componentes.

Cabral também propõe uma reflexão crítica sobre a atual configuração dos Parâmetros Curriculares relacionados à área de teatro no ensino fundamental, no ensino médio e no ensino superior. Para ela, a discussão dos PCNs para o ensino superior deve partir da constatação das necessidades do ensino fundamental e das "pedagogias invisíveis" (CABRAL, 2000) que orientam as atividades escolares e a prática teatral em sala de aula e na comunidade. Ao chamar a atenção para o fato de que existem múltiplas pedagogias e que nem todas são evidentes ao olhar menos atento, a autora aponta para a importância da promoção da sensibilidade do/a professor/a para que essas pedagogias possam se tornar visíveis e, sobretudo, objetos de análise, avaliação e, se for o caso, revisão e transformação. Muitas destas pedagogias invisíveis se configuram como reproduções de comportamentos, normas e valores culturais que são naturalizados e, por esse motivo, não são percebidos nem problematizados pelos professores.

Embora pretendam oferecer uma referência completa para o ensino e estudo das artes na escola, considero que os PCN-Arte infelizmente não exploram o potencial que o fazer artístico e, mais especificamente, as práticas cênicas/expressivas, em suas diversas instâncias, oferecem para o desenvolvimento cognitivo e emocional de crianças e jovens.

Para finalizar esse este tópico, gostaria de abordar algumas propostas alternativas que têm sido feitas à Abordagem Triangular, especialmente no que tange ao ensino de Teatro, que visam, sobretudo, torná-lo mais prático/vivencial e não excessivamente explicativo, bem como inserí-lo nas "poéticas e políticas" do ensinar arte na contemporaneidade. Uma destas alternativas de ensino-aprendizagem, especificamente voltada para as Artes Cênicas, é proposta por Graça Veloso (2008), professor de Teatro na UnB. Nela a triangulação é pensada sob a perspectiva das práticas cênicas, facilitando o estabelecimento de uma relação mais direta com os conteúdos curriculares de Teatro e suas possibilidades de trabalho em sala de aula, nos mais diversos níveis de aprendizagem. Como novos vértices desta triangulação, Veloso propõe: 1. Os registros historiográficos do teatro (análise e crítica da dramaturgia, do espetáculo e da teoria do teatro); 2. As tecnologias aplicadas ao espetáculo (cenografia, cenotécnica, maquiagem, iluminação, indumentária) e 3. Os fazeres do corpo (direção, encenação e interpretação). Ao enfocar as práticas cênicas em sua multiplicidade e multiculturalidade, Veloso chama a atenção para a necessidade de olhar para o Teatro não mais a partir da visão linear e historicista vigente nas matrizes curriculares brasileiras, ampliando o campo de atuação dos professores dispostos a repensarem os sentidos de fazer e ensinar teatro no século XXI.

Como resposta à Abordagem Triangular, encontramos também a inspiradora "Abordagem em Espiral", de Marina M. Machado (2012), professora de Teatro na UFMG. A autora propõe, "de maneira brincante”, que o/a educador/a da área de 
artes trabalhe de forma integrada e híbrida com as quatro linguagens artísticas, através das teatralidades, das corporalidades, das espacialidades e das musicalidades. Pautada em um dos criadores da chamada Antropologia da Performance, Victor Turner, Machado enxerga no professor um performer capaz de lidar com as novidades, com os estranhamentos, com as diferenças, e profundamente sintonizado com as "culturas da infância" (SARMENTO, 2003). Através de uma perspectiva "espiral", a autora propõe a criação "de uma espécie de currículo às avessas, a ser ensinado por meio de antimetodologias" (MACHADO, 2012, p. 9), com ênfase nos processos, e não nos produtos, na criatividade, na expressividade, nas dinâmicas histórico-político-sociais dos agentes envolvidos no ensino-aprendizagem de arte.

Inspirada por Veloso e por Machado, aproveito para reforçar a necessidade que percebo, mais premente a cada dia, de rompimento com a relação hierárquica tradicionalmente estabelecida tanto na prática, quanto no ensino do Teatro, que posicionava ora o dramaturgo, ora o diretor e, mais contemporaneamente, o ator, no topo da escala. Acredito, por um lado, que nenhuma metodologia de trabalho em teatro/com teatro seja absoluta ou aplicável em toda e qualquer realidade. Por outro lado, penso que elas devam acolher a riqueza pertinente à expressividade cênica em toda a sua abrangência, como uma linguagem artística que congrega, dialoga, "brinca" com outras artes e manifestações estéticas (danças, cantos, músicas, narrativas orais, festas, rituais, práticas circenses, etc.). Este transbordamento extremamente enriquecedor das fronteiras disciplinares e a noção de que a aprendizagem é processual, dinâmica, e envolve troca de experiências e saberes, provoca outros cruzamentos, fricções - ou f(r)icções, como propõe o antropólogo John Dawsey (2009) - entre os Estudos da Performance e a Pedagogia do Teatro.

\section{A Pedagogia do Teatro - uma nova categoria para novas demandas}

Atualmente, a terminologia "Pedagogia do Teatro" toma conta das discussões que ocorrem nas interfaces entre o Teatro e a Educação. Uma nova perspectiva de abordagem do ensino/aprendizagem do teatro caracteriza essa nomenclatura, cuja principal mudança em relação às abordagens mais tradicionais da Arte-Educação está no fato de não separar a prática teatral que ocorre no ambiente escolar da prática que é realizada por atores ou diretores, ou seja, por profissionais do teatro. Para este artigo escolhi quatro autores brasileiros que podem ajudar a compreender essa transformação conceitual, suas implicações na formação dos novos docentes da área de teatro e sua reverberação nas salas de aula e nas salas de treinamento e ensaio. São eles: Ingrid Koudela, Flávio Desgranges, Biange Cabral e Gilberto Icle, todos professores, de diferentes instituições e gerações, que têm realizado reflexões críticas sobre o tema.

Comecemos com uma pequena historicização do binômio Pedagogia do Teatro e Teatro na Educação. De acordo com Ingrid Koudela (2006, p. 161), que é professora na Escola de Comunicação e Artes da USP, a utilização da grafia Teatro/ Educação, com uma barra entre os termos, no início da década de 70, visava deixar em aberto as relações a serem estabelecidas entre ambos os campos de atuação. Ao longo desta mesma década, com a tradução do termo Art Education, em inglês, oriundo das 
Artes Visuais dos EUA, a grafia Teatro-Educação passou a vigorar nos congressos da Federação de Arte-Educadores do Brasil (FAEB) e da Associação de Arte-Educadores de São Paulo (AESP), nos quais a autora participara. A partir de então, o termo Arte-Educação generalizou-se englobando as outras áreas de conhecimento em artes, como o Teatro, a Dança e a Música, que passaram a ser concebidas como linguagens (o que se mantém até os dias de hoje, como vimos, inclusive nos PCNs), sob a égide conceitual, no entanto, das Artes Visuais.

O termo Pedagogia do Teatro é utilizado, inicialmente, em diferentes contextos, como na descrição dos processos de aprendizagem de teatro em distintas culturas realizada nas obras que dão suporte à Antropologia Teatral de Eugênio Barba, ou na proposta alemã de diálogo entre a pedagogia e a educação, Theaterpädagogik. Para Koudela (op. cit., p. 163):

O intuito de incorporar reflexões e indagações sobre a Pedagogia do Teatro visou não apenas a ampliar o espectro da pesquisa na área, trazendo para a discussão os Mestres do Teatro - dramaturgos, teóricos e encenadores -, como também fundamentar a epistemologia e os processos de trabalho do teatro, inserindo-os na história da cultura.

Adotando outra vertente de pesquisa bastante ligada ao desenvolvimento da Pedagogia do Teatro, Flávio Desgranges, também professor na ECA-USP, parte do pressuposto de que o teatro possui uma dimensão pedagógica intrínseca para encontrar no espectador o protagonista das novas relações instituídas pelo processo de desconstrução das ilusões cênicas. Segundo ele, é a partir de uma "Pedagogia do Espectador" (DESGRANGES, 2003) que estas relações podem ser conhecidas e aprofundadas, permitindo o desenvolvimento de uma arte do espectador, na qual este seja sujeito de um ato criativo, produtivo, autoral. Para o autor, se a atuação do espectador precisa ser tomada a partir de uma perspectiva artística, precisa-se também afirmar a necessidade de formação desse espectador - já que a capacidade de analisar (e, podemos pensar, fruir) uma peça teatral não é somente um talento natural, mas uma conquista cultural (DESGRANGES, 2006, 37)

Já Gilberto Icle, que é ator, diretor e professor na Faculdade de Educação da UFRGS, levanta as condições de emergência da pedagogia teatral como um eixo teórico-metodológico que aproxima diferentes instâncias do fazer teatral. Em sua pesquisa, o autor considera que as principais mudanças que definiram novas abordagens da prática teatral ocorreram não necessariamente nos espetáculos, mas nas salas de ensaio, escolas e laboratórios. Segundo ele, nas situações pedagógicas engrendradas por personalidades como Stanislavski, Meyerhold, Copeau, Grotowski ou Barba revelaram-se "a dinâmica e as relações indissociáveis entre o artístico e o pedagógico." (ICLE, 2009, 3). O autor vai elencar, então, alguns elementos que caracterizam essa que pode ser considerada uma mudança de paradigma, que ocorre no teatro ao longo do século XX e que orienta a relação deste com a educação. Entre estes elementos, ele inclui: 1) a instauração da improvisação como procedimento criativo; 2) a conversão do diretor num "diretor-pedagogo", que precisa criar um "ambiente pedagógico" para que consiga desenvolver seu processo de pesquisa e criação da encenação junto aos atores e aos demais membros da equipe; 3) a transformação do grupo de teatro em 
comunidade teatral, que não toma mais o espetáculo as ponto-chave do teatro, valorizando o processo criativo e o desenvolvimento de identidades teatrais localizadas social e culturalmente. Para Icle $(2009$, p. 8):

Aparentemente são nas mudanças, nas passagens, nas rupturas, nos movimentos, nas formas distintas e "novas" de fazer e pensar teatro que a aquilo que chamamos de Pedagogia do Ator foi se engendrando, se disciplinando, se constituindo como um discurso e uma prática verdadeira. Com efeito, ela se insinua nessa transcendência do espetáculo, nesse espaço, nesse locus, nesse entre-lugar, na fissura na qual transborda. É o movimento que possibilita a Pedagogia Teatral.

Debruçando-se de forma mais específica na Antropologia Teatral de Eugenio Barba, o autor aponta para as contribuições que esta pode aportar para o campo da Pedagogia do Teatro e, mais efetivamente, no ensino do teatro. Uma das principais contribuições passaria pela compreensão do conceito de pré-expressividade, ou seja, tudo aquilo que antecede o momento expressivo, de representação propriamente dita o que vem antes da cena, do palco, da dança. O conceito se estrutura sobre duas categorias opostas e complementares: o cotidiano e o extracotidiano, que mobilizam energias distintas, já que operam no sentido de alcançar diferentes objetivos. Barba identificou o que intitula de "princípios pré-expressivos" semelhantes em diferentes culturas, que permitiriam a constatação de que há uma dimensão que prepara, antecede e organiza a os corpos para o estado de atuação e que esta dimensão não está vinculada diretamente a um significado ou a um conteúdo. De alguma maneira, este embasamento empírico -reflexivo legitima a idéia de treinamento do ator - ou do trabalho com alunos, em sala de aula, desvinculado da idéia de uma montagem. O desenvolvimento dos princípios pré-expressivos com alunos e/ou atores os tornaria potencialmente expressivos, melhor preparados, assim, para atuar em uma situação extracotidiana - teatral. Respeitando o trabalho de descoberta individual de cada aluno dentro desses princípios, o/a professor/a também estaria exercitando uma forma de conduzir um processo no qual sua intervenção é limitada ao apoio no desenvolvimento do potencial criativo dos alunos.

As implicações dos conceitos de pedagogia do teatro, e teatro como pedagogia, no âmbito do Teatro na Educação, também são discutidas por Biange Cabral, professora de Teatro na UDESC. Se o primeiro identifica determinados métodos de ensino e planejamentos, o segundo prevê que toda atividade com a linguagem teatral em sala de aula já configura uma pedagogia, independente do planejamento. Para Biange (2007, p. 1), embora essa abordagem acentue uma dicotomia, o que sempre é arriscado, esse risco se justificado, pois acentua a especificidade do teatro face à função do planejamento de ensino e à questão da aquisição de conhecimentos próprios da área.

A autora, que tem defendido em diversos artigos a legitimidade e o valor do trabalho do/a professor/a de teatro, ao mesmo tempo em que aponta a importância de um planejamento que especifique os objetivos artísticos a serem explorados (linguagem cênica), estéticos (valores) e temáticos (aspectos do texto ou tema), também lembra que o/a docente deve permanecer sempre atento para o contexto de trabalho, considerando sempre a possibilidade de alterar o programa do curso de acordo com as demandas dos alunos. 
Finalmente, Biange traz ainda para a discussão a proposta de Henri Giroux, de uma pedagogia da possibilidade. A partir do conceito-chave de resistência, este autor propõe a autonomia dos docentes (e poderíamos pensar no caso específico dos docentes de teatro) no sentido de reagirem contra a preponderância das teorias dominantes e a reprodução pura e simples de elementos culturais alheios à sua própria cultura. $\mathrm{O} / \mathrm{a}$ professor/a deve assumir-se como um/a agente que encara a educação como um empreendimento político, social e cultural. Esta visão de educação permite a conexão necessária para passarmos ao debate sobre a relevância dos Estudos da Performance na Pedagogia do Teatro.

\section{Os Estudos de Performance e a Pedagogia do Teatro}

Este texto se aproxima do fim e o/a leitor/a pode estar se perguntando: mas o que define, afinal, os "Estudos de Performance"? Embora não seja possível, no âmbito deste artigo, realizar uma profunda apresentação deste campo, felizmente já podemos contar atualmente no Brasil com poucas, mas sólidas, produções bibliográficas que permitem uma excelente contextualização teórico-metodológica não apenas dos Estudos de Performance mas, sobretudo, da relação entre estes e a Educação. O dossiê temático da Revista Educação e Realidade, intitulado "Performance, Performatividade e Educação" (2010), com editoria de Gilberto Icle, inaugura a discussão no Brasil, acompanhado, algum tempo depois, pela coletânea organizada por Marcelo Andrade Pereira, intitulada "Performance e Educação: (des)territorializações pedagógicas (2013). Dentre os diferentes trabalhos presentes em ambas as obras, sobressaem alguns pontos em comum, que trago neste momento para amparar nossa discussão sobre a relação entre os Estudos Performance e a Educação e, mais especificamente, a Pedagogia do Teatro:

1. campos disciplinares preponderantes: artes, teatro, antropologia, sociologia, filosofia, literatura, psicologia, educação;

2. principais conceitos agenciados para tratar de performance: corpo, voz, gesto, movimento, presença, atuação, desempenho, processo, comunicação, contextualização, experiência, reflexividade, liminaridade, multiculturalidade, hibridismo, dialogismo, anti-estrutura, contaminação, fronteira, (linguagem) poética, política;

3. abordagens metodológicas: etnografia, observação participante, uso de técnicas e recursos audiovisuais.

4. autores de referência/bases teóricas: Richard Schechner, Victor Turner, Erving Goffman, J. Austin, Richard Bauman, Walter Benjamin, Diana Taylor, Paul Zumthor e, no Brasil, Renato Cohen, Regina Müller, Zéca Ligiéro, João Gabriel Teixeira, John Dawsey, Jean Langdon, Eleonora Fabião, entre outros;

Em minha pesquisa sobre o desempenho dos contadores de causos, especificamente, tenho adotado a proposição da antropóloga norte-americana Débora Kapchan (1995), que define a performance a partir de práticas estéticas que envolvem padróes de comportamento, maneiras de falar e maneiras de se comportar corporalmente. Segundo a autora, as repetições destas formas específicas de agir situam os atores 
sociais no tempo e no espaço, estruturando identidades individuais e de grupo. Com o passar dos anos, no entanto, passei a acrescentar a esta definição algumas outras características que considero fundamentais para pensar a performance, como o uso da linguagem poética, do corpo (incluída neste a voz) ser o veículo que dá forma ao que se quer comunicar ${ }^{4}$ (Per-formare) e de que todo ato de performance é reflexivo, cria uma experiência ao mesmo tempo que reflete sobre ela (HARTMANN, 2011).

A adoção do termo Pedagogia do Teatro, como vimos, insere o binômio ensino-aprendizagem em teatro, tanto dentro, quanto fora da sala de aula, num novo enquadramento epistemológico que contempla e enfatiza os contextos históricos-políticos-sociais no quais estes processos estão inseridos. Os Estudos da Performance, por sua vez, chamam a atenção para o papel dos sujeitos neste contexto, a importância que seus corpos, vozes, gestos, experiências, identidades étnicas, de gênero, raça e classe têm nos processos de construção de conhecimento. Como diz Schechner, a abordagem performativa do mundo permite compreendê-lo como um lugar em que reúnem-se ideias e ações:

Essa noção de reunião, de encontro, de interação da performance poderia ser tomada como um modelo para a Educação. Educação não deve significar simplesmente sentar-se e ler um livro ou mesmo escutar um professor, escrever no caderno o que dita o professor. A educação precisa ser ativa, envolver num todo mentecorpoemoçãotomá-los como uma unidade. Os Estudos da Performance são conscientes dessa dialética entre a ação e a reflexão. (SCHECHNER, 2010, p. 26)

Tanto ação, quanto reflexão, consideradas de um ponto de vista antropológico, ao qual minha formação sempre me remete, só existem "em contexto" e, neste sentido, em relação. Relação que se dá, fundamentalmente, entre corpos, vozes, memórias e experiências culturais de professores, alunos, parentes, cozinheiros, faxineiros, guardas de trânsito, atores, diretores, espectadores... Os Estudos da Performance, ao trazerem à tona a importância dos sujeitos, ativa e reflexivamente, tornam-se, neste sentido, especialmente pertinentes, pois atribuem valor à dinâmica das relações humanas.

Comunicar - e se comunicar - como já disse Viola Spolin (2001), deve sempre ser mais importante que o método utilizado para tanto. $\mathrm{O}$ cruzamento da Pedagogia do Teatro com os Estudos da Performance, acredito, potencializa as riquezas contidas nas diferenças culturais, étnicas, religiosas, de classe e de gêneros dos múltiplos sujeitos envolvidos nos processos de construção de conhecimento e troca de saberes através do Teatro.

\section{Referências}

BARBOSA, A. M. A imagem no ensino da arte: anos oitenta e novos tempos. São Paulo: Perspectiva; Porto Alegre: Fundação IOCHPE, 1991.

CABRAL, B. (Biange). Pedagogia do teatro e teatro como pedagogia. Anais da IV Reunião Científica de

Pesquisa e Pós-Graduação em Artes Cênicas. Belo Horizonte/MG, 2007. Disponível em: <http://www. portalabrace.org/ivreuniao/pedagogia.htm>. Acesso em: 20 dez. 2013. 
CABRAL, B. (Biange). Teatro e pressupostos curriculares. In: Subsídios para a reorganização didática no Ensino Fundamental. Florianápolis: Secretaria Municipal de Educação, p 223-232, 2000.

. O drama como método de ensino. São Paulo: Hucitec, 2006.

CACCIAGLIA, M. Pequena história do teatro no Brasil: quatro séculos de teatro no Brasil. São Paulo: Ed. Da Universidade de São Paulo, 1986.

CAFEZEIRO, E.; GADELHA, C. História do teatro brasileiro: um percurso de Anchieta a Nelson Rodrigues. Rio de Janeiro: Editora UFRJ: EDUERJ: FUNARTE, 1996.

CORAZZA, S. M. Diferença pura de um pós-currículo. In: LOPES, A. C.; MACEDO, E. (Orgs.). Currículo: debates contemporâneos. v. 2. São Paulo: Cortez, 2003.

DAWSEY, J. Corpo, máscara e f(r)icção: a "fábula das três raças” no Buraco dos Capetas. Ilha - Revista de Antropologia. Florianópolis: v. 11, n. 1, p. 41-62, 2009.

DESGRANGES, F. Pedagogia do teatro: provocação e dialogismo. São Paulo, Hucitec, Mandacaru, 2006.

DESGRANGES, F. A pedagogia do espectador. São Paulo: Hucitec, 2003.

Pedagogia do teatro: provocação e dialogismo. São Paulo: Hucitec/Edições Mandacaru, 2006.

HANSTED, T.; GOHN, Teatro e educação: uma relação historicamente construída. Eccos Revista Científica. São Paulo, n. 30, 2013, p. 199-220.

HARTMANN, L. Gesto, palavra e memória: performances de contadores de causos. Florianópolis: Ed. da UFSC, 2011a.

. Sobre o contar causos: performances narrativas em uma região de fronteira. In: CAMARGO, R. C.; REINATO, E. J.; CAPEL, H. S. F. (Orgs.). Performances culturais. São Paulo: Goiânia: Hucitec/PUC, 2011b, p. 336-347.

GUSMÃO, N. M. M. de. Antropologia, estudos culturais e educação: desafios da modernidade. Pro-Posições, v. 19, n. 3, (57), p. 47-82, set./dez. 2008.

ICLE, G. Da Pedagogia do Ator à Pedagogia teatral: verdade, urgência, movimento. O Percevejo online. v. 1- Fascículo 02, jul./dez./2009, p. 1-9. Disponível em: <http://www.seer.unirio.br/index.php/opercevejoonline/article/viewFile/525/461>. Acesso em: 19 dez. 2013.

. Para apresentar a performance à educação. Revista Educação \& Realidade. Porto Alegre: v. 35, n. 2, p. 11-22, 2010.

KAPCHAN, D. A. Common ground: keywords for the study of expressive culture: performance. Journal of American Folklore. v. 108, n. 430, 1995.

KOUDELA, I. A nova proposta de ensino do teatro. Sala Preta. n. 02, 2002. Disponível em: <http://www. eca.usp.br/salapreta/PDF02/SP02_031_koudela.pdf>. Acesso em: 28 nov. 2013.

. Pedagogia do teatro e teatro na educação. Anais do Congresso Nacional da Federação de Arte-Educadores do Brasil: trajetória e políticas do ensino de artes no Brasil. Rio de Janeiro: FUNARTE; Brasília: FAEB, 2006.

MACHADO, M. M. Fazer surgir antiestruturas: abordagem em espiral para pensar um currículo em arte. Revista e-curriculum, São Paulo, v. 8 n. 1, 2012, p. 1-21. 
PEREIRA, M. de A. Performance e educação: (des)territorializações pedagógicas. Santa Maria/RS: Ed. da UFSM, 2013.

PEREGRINO, Y.; SANTANA, P. A. Ensinando Teatro: uma análise crítica das propostas dos PCNs. 2001. Disponível em: <http://www.cchla.ufpb.br/pesquisarte/publicacoes.html>. Acesso em: 18 jan. 2014.

RICHTER, I. M. Multiculturalidade e interdisciplinaridade In: BARBOSA, A. M. (Org.). Inquietações e mudanças no ensino da Arte. 4. ed. São Paulo: Cortez, 2008.

SCHECHNER, R. O que pode a performance na educação. Revista Educação \& Realidade. Porto Alegre: v. 35, n. 2, 2010, p. 23-35.

SPOLIN, V. Improvisação para o teatro. São Paulo: Perspectiva, 2001.

VELOSO, G.; SANTANA, A. P. Módulo 14: História da srte-rducação. Programa Pró-Licenciatura em Teatro-UnB Brasília: Dupligráfica, 2008.

\section{Notas}

${ }^{1}$ Para maior aprofundamento no tema, ver artigo recente de Hansted e Gohn (2013), onde consta um levantamento da relação entre Teatro e Educação ao longo da história e um debate sobre a diversidade teórico-metodológica de abordagens no contexto brasileiro atual.

${ }^{2} \mathrm{O}$ "mito das três raças" é a tradução crítica de uma determinada leitura sociológica do Brasil, originada com Gilberto Freyre, que afirma uma participação igualitária das três "raças", branco (português), negro (escravo africano) e índio (nativo) na formação da sociedade brasileira.

${ }^{3}$ Pineau, conforme nos informa Icle (2010) é uma das pioneiras na interseção entre Performance e Educação. Importante ressaltar ainda que a autora, norte-americana, assume ter sido francamente inspirada na educação libertadora de Paulo Freire para o desenvolvimento de sua pedagogia performativa crítica.

${ }^{4}$ Interessante perceber na etimologia da palavra, par former, de origem francesa, sua primeira acepção já ligada ao dar forma (ao conhecimento, à experiência, à imaginação, etc.). Ver Hartmann (2011a).

* Professora Doutora do Departamento de Artes Cênicas e do Programa de Pós-Graduação em Arte da Universidade de Brasília, Brasília, Distrito Federal, Brasil.

\section{Correspondência}

Luciana Hartmann - Universidade de Brasília, Departamento de Artes Cênicas. Complexo das Artes Campus Darcy Ribeiro, Asa Norte, CEP: 70910000 - Brasilia, Distrito Federal - Brasil.

E-mail: luhartm71@gmail.com

Recebido em 13 de fevereiro de 2014

Aprovado em 09 de julho de 2014 